\title{
Inclusive Early Childhood Settings: Analyses of the Experiences of Thai Early Childhood Teachers
}

\author{
Sunanta Klibthong ${ }^{1}$ \& Joseph Seyram Agbenyega ${ }^{2}$ \\ ${ }^{1}$ Ratchasuda College, Mahidol University, Salaya, Thailand \\ ${ }^{2}$ Faculty of Education, Monash University, Melbourne, Australia \\ Correspondence: Sunanta Klibthong, Ratchasuda College, Mahidol University, Salaya, Thailand.
}

Received: August 8, 2019

doi:10.5539/ies.v13n1p21
Accepted: September 12, 2019 Online Published: December 17, 2019

URL: https://doi.org/10.5539/ies.v13n1p21

\begin{abstract}
Findings from child development research support inclusive practice in early childhood education to enable full participation of all children in learning activities and build their core capabilities for life. However, the implementation of inclusive practices in early childhood is often constrained by boundary-crossing barriers. This paper reports a quantitative study that investigated and analysed the inclusive practice experiences of 344 pre-school teachers across the six regions of Thailand. The study identified positive experiences of inclusive practices linked to effective collaboration with minimal barriers related to time, increased workload and lack of resources to help teachers cater to the needs of all children. The findings offer direction for developing teachers as leaders to work effectively across professional boundaries so that Thailand can achieve the goals of inclusive education for all children.
\end{abstract}

Keywords: early childhood, leadership, inclusive education, Thailand

\section{Introduction}

This paper explored professional experiences of early childhood teachers in six regions in Thailand. The purpose is to measure how the teachers rated their inclusive education professional practice experiences, and illuminate how to support improvements in professional practice for inclusion to realize its primary objectives of quality education for all children. With this purpose in mind, the paper addresses inclusive education as a leadership issue which must involve teachers, school principals, families, and policy makers. We propose a team approach to facilitate boundary spanning in inclusive education practice. Lupton and Jones $(2002$, p. 1) defined inclusive school as "an effective school and one in which the teaching and learning, achievements, attitudes and wellbeing of every student matter." Inclusive schools embrace all students and continuously transform their culture and practices to offer new opportunities to those who might have experienced previous educational difficulties and exclusion (Armstrong, 2006; Lupton \& Jones, 2002). Our definition of early childhood inclusive education is the degree to which the quality of the early education program orchestrated through effective leadership can enable individual children to belong, feel safe and supported to utilize early childhood education to develop core capabilities for life (Klibthong \& Agbenyega, 2018). This definition places inclusive education in the context of policy, pedagogical and administrative leadership. In the pursuit of educational equity and inclusion, the nature of leadership drives support systems and practices to ensure all children thrive in their learning (Liasidou \& Antoniou, 2015).

Education policy documents worldwide have focused strongly on the rights of every child to receive quality education and build the skills needed for life-long learning and full participation in society (Deppeler, Loreman, \& Smith, 2015). It also includes the right to care, wellbeing and quality education for children, who are underprivileged by birth, cultural and economic circumstances that predispose them to discrimination (Slavin, 2017). In early childhood educational settings, students with a disability/additional education needs may experience different learning challenges. Ongoing decision-making that adopts practices based on evidence of equity and quality can improve teaching and learning in the classroom for young children with disability and/or additional needs (Jordan \& McGhie-Richmond, 2014).

The approaches that teachers adopt to teach children to learn and thrive depend on the collaborative and consultative culture developed within a school where the best intension is to offer resources to support and enhance the ability of all children (Jordan \& McGhie-Richmond, 2014). Notwithstanding the attractiveness of inclusion, its 
implementation faces many challenges as reported in previous studies (DiPaola \& Walther-Thomas, 2003; Florian, 2008; Sharma \& Desai, 2008). One prominent challenge of inclusion is leadership capability to drive the inclusion vision (Angelides, 2012; Harris, 2005; Timothy \& Agbenyega, 2018). When teachers develop their professional capabilities to the level of pedagogical leaders, they improve the effectiveness of inclusive practices in schools (Florian, 2008). The research question that this research focused on was: How do Thai early childhood teachers rate their professional practice experiences of inclusive education?

\subsection{Leadership, Inclusive Education, and Boundary Crossing}

Teachers and program leaders who believe that all children can learn if the right learning environment and support are provided often, create inclusive early childhood environments (Liasidou \& Antoniou, 2015). Principals or school leaders therefore, are critical in the success of inclusive education. The way teachers perceive the boundaries between them and their principals can affect their practice of inclusion (Sharma \& Desai, 2008). Boundaries indicate limits, borders or bounds that can be conceptual, philosophical, paradigmatic or physical (Ernst \& Yip, 2009). In inclusive education, boundaries can present both opportunities and barriers depending on how teachers, therapists, families and principals work together in their schools' communities to counter barriers imposed by boundaries (Blase \& Anderson, 1995; Liasidou \& Antoniou, 2015).

It is claimed that the quality of early childhood inclusive practice lies in the ability of professionals to work effectively across vertical, demographic, geographic and stakeholder boundaries (Yip, Ernst, \& Campbell, 2009). In relation to vertical boundaries, members of the inclusive school community work across levels and hierarchy of authority and power, and in terms of horizontal boundaries they implement cross-functional collaboration (Harris, 2005). Geographical boundaries relate to working across different contexts in terms of distance and location while demographic boundaries relate to working across diverse cultural, religious, age and class groups (Williams \& Berry, 2016). To create a positive learning environment for all children in inclusive programs, educators need to work across stakeholder boundaries and create alliance with external partners such as families and communities (Akkerman \& Bruining, 2016; Northouse, 2013) for the befit of all children.

Perhaps the most critical aspects of successful inclusive early childhood program is where members of the school's community are able to work collaboratively across levels and authority such as professional titles and ranks, and power and privilege (Harris, 2005; Liasidou \& Antoniou, 2015). This process entails breaking down hierarchies of power so that teachers can build a strong collaborative practice (Ernst \& Yip, 2009). Again, teachers, parents and principals need to build bridges across horizontal boundaries. This happens when all parties recognize that they need each other and thus, value and bring experiences and expertise to actively participate in the inclusive education process (Lalonde, 2013). Parents are considered the key stakeholders in the education of their children. Studies found that when teachers and school leaders work together to build bridges across stakeholder boundaries, they open up opportunities for mutual solutions for resourcing inclusive schools to benefit all children (Klibthong \& Agbenyega, 2018; Ryan, 2006; Sharma \& Desai, 2008).

Literature on inclusive education in Thailand identified several issues that affect the smooth implementation of inclusive education. These include some members of Thai society who perceive disability as the act of reincarnation (Klibthong \& Agbenyega, 2013), cultural values that consider education of persons with disability as an act of charity and pity, as well as policy-practice effectiveness, and insufficient financial support for inclusive education (Klibthong \& Agbenyega, 2013; Vorapanya \& Dunlap, 2014). Kantavong (2018) found that school leaders in Thailand were generally supporting inclusive education but were inhibited by teacher quality and financial support issues. Despite financial barriers school leaders' support is boosting teachers' morale to teach students with special education needs. In addition, parents of general education students are also showing increased acceptance of inclusive education (Kantavong, 2018).

Indeed, at the practices level, variations of inclusive practice effectiveness are based on school administrators' support for teachers, policy effectiveness (Kantavong, 2018; Timothy \& Agbenyega, 2018), and the quality of the teacher workforce (Klibthong \& Agbenyega, 2018). Despite these findings, we know little about the inclusive practice experiences of early childhood teachers in six regions of Thailand. Thus, this study is timely and provides some insights into the inclusive practice experiences of Thai early childhood teachers.

\subsection{Conceptual Framework}

This study applies the concept of boundary spanning from business leadership to inclusive education. Inclusive school system at the early childhood levels operates with many different layers and components as outlined previously. Inclusive education is a system that works with therapists, families, psychologist, special educators, teachers and principals. The ever-increasing complexity and interdependence of inclusive school systems "call for a critical transformation in leadership from managing and protecting boundaries to boundary spanning-the 
capability to create direction, alignment, and commitment across boundaries in service of a higher vision or goal" (Yip, Ernst, \& Campbell, 2016, p. 2). Traditionally, early childhood educators work independent of therapists and families and the same applies to principals who manage their school systems vertically as bosses (Harris, 2005). When members of the inclusive school community realize their interconnectedness, they are able to work effectively across functions, contexts, and with families (Heikka \& Waniganayake, 2011).

According to Yip, Ernst, and Campbell (2016, p. 12) boundary spanning leadership entails "the transformation of organizations from rigid hierarchical structures to networked structures with flows of people, information, and resources across boundaries." In the inclusive school settings, school leaders need to develop strategies to manage boundaries by clarifying roles, purposes and areas of specialization for members of the inclusive school community in order to build safe school practices and respect across professional boundaries (Akkerman \& Bruining, 2016). There is the need also, for developing common understanding by identifying and strengthening what is universally important and shared by all members of the school community. According to Akkerman and Bruining (2016, p. 242), a boundary crossing perspective allows a more fine-grained understanding of the required new relationships and cultural perceptions, as it is specifically targeted at analyzing challenges and learning opportunities of situations in which diverse stakeholders (e.g., different disciplines or institutions) need to collaborate.

Teachers who work with others to combine ideas and shared vision into a unified force can enhance trust, engagement and shared ownership across any type of boundaries. It is through these processes that new frontiers for orchestrating effective inclusive practice can be realized and positive experiences enhanced. Research findings suggest that boundary crossing leadership can help discover intersection where groups collide, criss-cross and relate (Harris, 2005; Ryan, 2006). Practitioners who value others' skills create a solid team of differentiated expertise, experience, and resources that are driven by an inclusive vision and strategy in order to support innovation and transformative inclusive practices (Akkerman \& Bakker, 2011; Sharma \& Desai, 2008).

\subsection{Context of This Research}

Inclusive practice experiences are best understood when an explicit account is given about the context of practice. Contexts in this sense are factors external to the implementation of inclusive practice that may act as barriers or facilitators to its effectiveness (Banks, Shevlin, \& McCoy, 2012). This may include education and disability policies, teaching resources, technology and infrastructure. Implementation of inclusive education often varies from one context to the other with potential for different outcomes. Inclusive education works by introducing strategies that are sufficiently appropriate to their context to produce optimum outcomes for all children (Bourke, 2017). This in effect, will minimize teacher concerns because challenges are targeted during implementation. The research context provides information to illuminate the findings.

We conducted this research in Thailand, a country with 6 regions and 77 provinces. Participants were selected from all the six regions by purposeful invitation. The Thai government passed Persons with Disabilities Empowerment Act, B.E. 2550 by incorporating education as a human right that entitles all Thai persons with disability including preschool-aged children to quality education (Vibulpatanavong, 2017). In 2008, the Government of Thailand approved Education for Persons with Disabilities Act B.E. 2551 with emphasis on free education from birth; or when a disability occurs until the end of life. This policy places emphasis on the provision and use of educational technologies and early intervention services to support all children with diverse abilities to have the best start in life (Bualar, 2016; Vibulpatanavong, 2017). Important aspects of this Act include a focus on equity, quality assurance within the curriculum, instruction, assessment that are to be appropriate to the need of each type of disability and each learner. These Acts were followed by 2017 National Education Plan for education (Year 2017-2036) which sets five major goals to be achieved by the year 2036, one of which is ensuring quality education and resource access to all learners (Office of the Educational Council, 2016; Thai Ministry of Education, 2017; Vibulpatanavong, 2017). This policy resonates with Education For All (EFA) principles. The national education plan refers to inclusive education as education for all learners (Thai Ministry of Education, 2017), which provides a set of guiding principles and goals for the country to improve inclusive education justifying the need to explore teachers' concerns.

\section{Method}

We obtained ethical permission from Mahidol University and undertook a quantitative study of preschool teachers across six regions of Thailand who were teaching in preschool educational settings described as inclusive. Early childhood teachers who work in early childhood schools that provide education for both students with and without disabilities/additional education needs met the inclusion criteria. We used a 22-item self-developed questionnaire to gather data with the view of reaching a large representative sample. 


\subsection{The Sample}

We wanted to explore the perspectives of preschool teachers with a wide range of experiences on issues regarding administrative and family support and the adequacy of their professional preparation in implementing inclusive education for young children in Thailand. After obtaining ethical approval from Mahidol University, in Thailand, we contacted preschool principals in the six regions to find out if their schools educate children with disabilities. Then we purposefully sampled schools in each region that were described as inclusive which had a minimum of 15 children with official diagnosis of disability enrolled. Thirdly, we used a comprehensive sampling to invite all the teachers from these schools by emailing potential participants to participate in the study. Our emails were accompanied with explanatory statements and consent forms. After we received confirmation from potential participants, we sent the questionnaires to 413 participants and 344 returned the questionnaires indicating $83 \%$ response rate. We noted that the use of emails facilitated quicker distribution and return of the questionnaires. Our final sample reported in this paper comprised of 344 participants who played different roles in their schools. We report further details on the participants' characteristics in the findings section.

\subsection{Instrument and Techniques of Analysis}

We constructed a 22-item scale and used it to examine 344 teachers' concerns of preschool inclusive practice across six regions of Thailand. The items were measured on a five-point Likert scale of 1-Not at all concerned to 5-Extremely concerned. Computation of the internal reliability of the responses to the questionnaire yielded a high reliability Cronbach's alpha coefficient of 0.954 . Item mean was 3.4 and variance was 0.02 . This showed that the items were highly reliable for use in this study to measure teachers' perspectives regarding their experiences. We used SPSS version 24 to analyse the data. We computed descriptive statistics and extracted percentages on the participants' response to each item on the questionnaire. We also conducted independent sample t-tests and analysis of variance to determine differences in experiences.

\subsection{Respondent's Profile}

The 344 participants were from six different regions of Thailand as follows: Northern Region $14 \%(n=48)$, Bangkok Metropolitan Region 18\% ( $\mathrm{n}=61)$, North Eastern 27\% ( $\mathrm{n}=93)$, Western Region $8 \%(\mathrm{n}=27)$, Eastern Region $15 \%(\mathrm{n}=52)$, and Southern Region $18 \%(\mathrm{n}=63)$. In terms of gender, the majority of the participants were female $97 \%(n=333)$ and $3 \%(n=11)$ were males. A great majority of the participants worked in government kindergartens $90 \%(\mathrm{n}=308)$ and the rest in the private kindergarten sector $11 \%(\mathrm{n}=36)$. Regarding qualification, most of the participants were Bachelor degree holders $86 \%(n=297)$, followed by Diploma $6 \%(n=22)$, Master's degree $4 \%(n=14)$, and Certificate $3 \%(n=11)$. In terms of professional roles, the majority were classroom teachers $90 \%(\mathrm{n}=309), 2 \%(\mathrm{n}=8)$ described themselves as administrators in the school, and $8 \%(\mathrm{n}=27)$ as teacher assistants. The results are surprising because none of the participants indicated roles as therapists or early intervention specialists although we asked questions related to these roles. Out of the 344 participants who returned the questionnaires $67 \%(\mathrm{n}=230)$ indicated that they worked with children with disability on a daily basis in their schools and $33 \%(\mathrm{n}=114)$ on occasional basis. The participants' age and experience in terms of years are reported in Tables 1 and 2.

Table 1. Age in years

\begin{tabular}{cc}
\hline Age & $\%(\mathrm{~N})$ \\
\hline$<20$ & $0.9 \%(\mathrm{n}=3)$ \\
$20-29$ & $21.2 \%(\mathrm{n}=17)$ \\
$30-39$ & $34.9 \%(\mathrm{n}=120)$ \\
$40-49$ & $26.5 \%(\mathrm{n}=91)$ \\
$50+$ & $16.6 \%(\mathrm{n}=53)$ \\
\hline
\end{tabular}

Table 2. Teaching experience in years

\begin{tabular}{cc}
\hline Years in rage & $\%(\mathrm{~N})$ \\
\hline$<5$ & $20.9 \%(\mathrm{n}=72)$ \\
$5-10$ & $32.6 \%(\mathrm{n}=112)$ \\
$11-15$ & $15.1 \%(\mathrm{n}=52)$ \\
$16-20$ & $15.7 \%(\mathrm{n}=54)$ \\
$21+$ & $15.7 \%(\mathrm{n}=54)$ \\
\hline
\end{tabular}




\section{Findings}

\subsection{Supportive Working Environment}

The purpose of this research study was to explore the inclusive teaching experiences of Thai early childhood teachers. The participants' responses to each question were analysed using descriptive statistics, including frequencies, means, standard deviations and percentages. The means and standard deviations of how the participants responded to practices and processes that enhanced their inclusive education implementation experiences in the early childhood settings are reported in Table 3 . The findings demonstrate diversity in responses to different items. While most teachers agree that their education background had prepared them to effectively teach students with disabilities $(\mathrm{M}=3.84, \mathrm{SD}=.76)$, generally, teachers felt strongly that they need more training in order to support all children to learn in inclusive early childhood settings $(\mathrm{M}=4.14, \mathrm{SD}=.74)$. 14. There was also a strong feeling by most of the participants that a positive relationship between teachers and teacher assistants can influence the quality of the support they provide for children with disability in inclusive classroom $(\mathrm{M}=4.06$, $\mathrm{SD}=.69)$.

Table 3. Means and standard deviations of responses to experience items

\begin{tabular}{|c|c|c|c|}
\hline Items & & Mean & Std. Dev. \\
\hline 1. & My educational background has prepared me well to effectively teach students with disabilities. & 3.84 & .76 \\
\hline 2. & I need more training to appropriately teach children with disabilities. & 4.14 & .74 \\
\hline 3. & I feel comfortable in working collaboratively with special education teachers when & 307 & 72 \\
\hline 4. & I have children with disabilities in my classroom. & 3.91 & .12 \\
\hline 5. & There is not enough administrative support to implement inclusive education program. & 3.39 & .95 \\
\hline 6. & I am confident to teach in inclusive classroom. & 3.43 & .93 \\
\hline 7. & I feel frustrated when I teach children with and without disability in my classroom. & 2.74 & 1.10 \\
\hline 8. & I feel overburdened when I have children with disability in my classroom. & 2.84 & 1.15 \\
\hline 9. & $\begin{array}{l}\text { I feel supported by my school principal when faced with challenges presented by children with behavioral } \\
\text { difficulties in my classroom. }\end{array}$ & 3.46 & .98 \\
\hline 10. & $\begin{array}{l}\text { Inclusive classroom experiences create and build environment in which both children develop social } \\
\text { understanding among themselves. }\end{array}$ & 3.88 & .79 \\
\hline 11. & In this school, parents work collaboratively with teachers to support children with disabilities. & 3.57 & .90 \\
\hline 12. & I feel comfortable including children with disabilities into my classroom. & 3.12 & 1.04 \\
\hline 13. & The therapists in my school work collaboratively with staff. & 3.26 & .90 \\
\hline 14. & I adapt my teaching to meet the needs of all children. & 3.94 & .57 \\
\hline 15. & $\begin{array}{l}\text { The relationship between the teaching assistant and teacher has a major impact on the effectiveness of support } \\
\text { arrangements for children with disability in inclusive classroom. }\end{array}$ & 4.06 & 69 \\
\hline 16. & I do not have enough time to design educational programs for students with disabilities. & 3.77 & .85 \\
\hline 17. & $\begin{array}{l}\text { Parents of children without disabilities do not like the idea of placing their children in the same classroom where } \\
\text { there are students with disabilities. }\end{array}$ & 3.20 & .93 \\
\hline 18. & My workload has increased because of inclusion. & 3.32 & 1.04 \\
\hline 19. & My performance as a teacher/school principal has declined. & 2.63 & 1.04 \\
\hline 20. & It is difficult to give equal attention to all students in an inclusive classroom. & 3.17 & 1.09 \\
\hline 21. & It is always difficult to maintain discipline in an inclusive classroom. & 3.21 & 1.11 \\
\hline 22. & There are inadequate resources/special teachers/staff available to support inclusion. & 3.73 & 1.00 \\
\hline 23. & I like being the only teacher in the classroom. & 2.58 & 1.21 \\
\hline
\end{tabular}

The findings of this research suggest that the most prevalent practices adopted to achieve these as evident in the participants' responses, were by being well-prepared professionally to effectively teach students with disabilities $81.4 \%(\mathrm{n}=280)$; working together as leaders to develop and build environments in which both children with and without disabilities develop social understanding among themselves $82.5 \%(\mathrm{n}=384)$, and being supported by the school principal when faced with challenges presented by children with behavioural difficulties in their classrooms $62.6 \%(\mathrm{n}=215)$. Other practice experiences include comfortability in working collaboratively with special education teachers when there are children with disabilities $85.1 \%(\mathrm{n}=293)$; adapting teaching to meet the needs of all children $88.7 \%(n=305)$; having a good relationship between teaching assistants and teachers to impact on the effectiveness of support arrangements for children with disability in inclusive classrooms $89.5 \%(\mathrm{n}=308)$; and recognising the need for further professional development in order to appropriately teach children with disabilities 
$91.9 \%(\mathrm{n}=316)$.

\subsection{Differences in Perspectives Pertaining to Regularly Teaching or Not Teaching Students with Disabilities in Class}

We conducted independent samples t-test to find out whether there were differences in experiences regarding teachers who had students with disabilities in their classes and those who did not. Of the 344 participants, 229 responded that they had children with disabilities in their classrooms and 113 indicated that they did not have any child with disability in their class. Two participants did not answer this question. The t-test showed that there were significant differences in the scores obtained from those who had students with disability in their classes and those who did not pertaining to three questionnaire items $(2,3 \& 12)$. These are; "need more training in order to appropriately teach children with disabilities." Teachers who have regular students with disability in their classes $(\mathrm{M}=4.21, \mathrm{SD}=.68)$ and Teachers who did not have regular students with disability in their classes $(\mathrm{M}=4.0$, $\mathrm{SD}=.81) ; \mathrm{t}(2.554), \mathrm{p}=.01$; "feel comfortable in working collaboratively with special education teachers when children with disabilities are in the classroom." Teachers who have regular students with disability in their classes $(\mathrm{M}=4.05, \mathrm{SD}=.65)$ and Teachers who did not have regular students with disability in their classes $(\mathrm{M}=3.40$, $\mathrm{SD}=.82) ; \mathrm{t}(3.030), \mathrm{p}=.003$; and "The therapists in my school work collaboratively with staff." Teachers who have regular students with disability in their classes $(\mathrm{M}=3.19, \mathrm{SD}=.96)$ and teachers who did not have regular students with disability in their classes ( $\mathrm{M}=3.40, \mathrm{SD}=.77) ; \mathrm{t}(-1.189), \mathrm{p}=.04$.

The differences suggest that teachers who encounter children with disabilities on daily basis require more training to improve their work and feel more comfortable in working collaboratively with special education teachers than those without regular children with disabilities in their classes. On the contrary, teachers without regular children with disabilities appeared to be more accepting that therapists in their school work collaboratively than teachers with regular students with disabilities in their schools.

\subsection{Differences in Perspectives Pertaining to Regions}

We conducted a one-way between groups ANOVA on the 22 items to explore the impact of geographical location of the teachers on their experiences of inclusive practice. Participants were divided into six groups according to their regions (Northern Region, Bangkok Metropolitan Region, North Eastern, Western Region, Eastern Region and Southern Region). There was a statistically significant difference at the $p<.05$ level in scores pertaining to the question, "Parents of children without disabilities do not like the idea of placing their children in the same classroom where there are students with disabilities" for six groups $F(5,338)=2.68, \mathrm{p}<.02$. Despite attaining statistical significance, the actual difference in mean scores between groups was quite small. The effect size, calculated using eta squared, was .04. According to Cohen (1988) this indicates a small effect size. Post-hoc comparisons using the Tukey HSD test indicated that the mean score for Bangkok Metropolitan Region $(\mathrm{M}=3.11$, $\mathrm{SD}=1.03)$; Western Region $(\mathrm{M}=3.44, \mathrm{SD}=1.01)$; Southern Region $(\mathrm{M}=3.44, \mathrm{SD}=0.94)$; Eastern Region (3.12, $\mathrm{SD}=0.83)$; and Northern Eastern Region $(\mathrm{M}=3.23, \mathrm{SD}=0.95)$ were significantly different from Northern Region $(\mathrm{M}=2.88, \mathrm{SD}=0.70)$. There was no statistically significant difference in mean scores between the other regions.

\subsection{Differences in Perspectives Related to Length of Professional Experience}

We conducted a one-way between groups ANOVA on the 22 items to test the impact of years of experience of the teachers on their perspectives related to inclusive practice. Participants were divided into five experience groups (Less than 5yrs, 5-10yrs, 11-15yrs, 16-20yrs and 21+yrs). There was a statistically significant difference at the $\mathrm{p}<.05$ level in scores pertaining to the question, "My educational background has prepared me well to effectively teach students with disabilities" $\mathrm{F}(4,339)=2.84, \mathrm{p}=.02$, and "There is not enough administrative support to implement inclusive education program" $F(4,339),=5.64, p=.00$. Though the data show statistical significance, the actual difference in mean scores between groups was quite small for item 1 and moderate for item 2 . The effect size, calculated using eta squared, were .03 and .06 respectively. Post-hoc comparisons using the Tukey HSD test indicated that the mean scores pertaining to educational background had prepared them are reported in Tables 4 and 5 respectively. 
Table 4. Post-hoc comparisons of means and standard deviations for educational preparation

\begin{tabular}{ccc}
\hline Teaching experience in years & Mean & St. Dev. \\
\hline Less than 5yrs & 3.76 & 0.68 \\
$5-10$ & 3.92 & 0.65 \\
$11-15$ & 3.56 & 0.89 \\
$16-20$ & 3.93 & 0.87 \\
$21+$ & 3.96 & 0.80 \\
\hline
\end{tabular}

Table 5. Post-hoc comparisons of means and standard deviations for insufficient administrative support

\begin{tabular}{ccc}
\hline Teaching experience in years & Mean & St. Dev. \\
\hline Less than 5yrs & 2.97 & 0.95 \\
$5-10$ & 3.43 & 0.93 \\
$11-15$ & 3.50 & 0.96 \\
$16-20$ & 3.72 & 0.86 \\
$21+$ & 3.44 & 0.95 \\
\hline
\end{tabular}

The findings confirmed that the least experienced teachers with less than 5 years teaching needed more administrative support than the most experienced teachers.

\subsection{Barriers to Working Effectively in the Inclusive Schools}

The prevailing barrier mitigating against the teachers' practice experiences to supporting all children was having enough time to design educational programs for students with disabilities. The majority of the participants $76.5 \%$ $(n=263)$ indicated they were constrained with time to develop effective inclusive programs, followed by inadequate resources/special teachers/staff available to support inclusion $74.7 \%(n=257)$. Another notable barriers were a feeling of increased workload because of inclusion $56.3 \%(\mathrm{n}=194)$ and difficulty maintaining discipline in the inclusive classroom $55.8 \%(\mathrm{n}=192)$.

\section{Discussion and Implication}

The purpose of this study is to present the experiences of early childhood teachers on their inclusive practice taking a leadership angle. The findings are interesting and contrary to most previous studies which found that teachers did not like inclusive practices because of lack of adequate professional preparation and inadequate support from school leaders (Armstrong, 2006; Carrington, Deppeler, \& Moss, 2010). It appears that these teachers are working as leaders in their schools despite having some common barriers such as lack of time to plan, and inadequate resources to support their work. Studies have found that teachers who feel positive about their programs and themselves as being well prepared to carry out their professional responsibilities are able to take leadership roles and initiate innovative teaching activities in inclusive schools (Angelides, 2012; Lupton \& Jones, 2002). This positive feeling was shown by the participants in this research when the majority reported that their educational background had prepared them well to teach students with disabilities $(\mathrm{M}=3.84, \mathrm{SD}=.76)$ and that inclusive classrooms experiences enable all children to develop social understanding among themselves $(\mathrm{M}=3.88, \mathrm{SD}=.79)$. These positive perspectives as the results showed in Table 3 resonate with previous studies which indicate that in order to improve inclusive culture in preschools, teachers and school principals need to have positive attitudes, collaborate and work across professional and stakeholder boundaries as pedagogical leaders (Akkerman \& Bakker, 2011; Liasidou \& Antoniou, 2015). Being a pedagogical leader means, having positive attitudes and versatility in planning and a devotion to constant adaptation and teamwork to serve the interests of all children (Akkerman, \& Bruining, 2016; Loo \& Agbenyega, 2015). This is different from management, which is characterised by the predisposition to direct people and adhere to inflexible routines (Lalonde, 2013).

In addition, the results demonstrate the teachers' self-awareness that they need more training to successfully teach students with special education needs in inclusive classrooms $(\mathrm{M}=4.14, \mathrm{SD}=.74)$. This is consistent with the idea of leadership qualities of self-improvement as well as and a broad vision for orchestrating quality inclusive education (Florian, 2008). It is argued that continuous self-improvement enables teachers to act as pedagogical leaders and offer rich, stimulating environments for all children's learning for their overall development (Timothy \& Agbenyega, 2018). This is in line with what Woodrow and Busch (2008) suggest that leadership should be infused into teachers' day-to-day pedagogical practices. In addition, the results confirmed the teachers' support for seeing the relationship between the teaching assistant and themselves as having major impact on the effectiveness inclusive education for students with disability in inclusive classrooms $(\mathrm{M}=4.06, \mathrm{SD}=.69)$. This confirm previous 
research which suggest that when teachers act as pedagogical leaders, they become activists who actively engage with every member of the school's community including families, for the benefit of all children (Akkerman \& Bruining, 2016; Loo \& Agbenyega, 2015).

The findings indicate that the embodiment of the identity as leaders in inclusive school is a prerequisite to educators understanding the needs of all children (Heikka \& Waniganayake, 2011). Pedagogical leaders are teachers who trust their own professional skills. In this sense, it would be impractical to expect to create effective inclusive schools and practices that support all children to thrive, while having teachers who find it difficult to believe in their professional capabilities or work together and support one another (Williams \& Berry, 2016).

The findings identified that teachers encountered some barriers in their daily inclusive practices including time constraints $(\mathrm{M}=3.77, \mathrm{SD}=.85)$, increased workload $(\mathrm{M}=3.32, \mathrm{SD}=1.04)$ and lack of adequate resources $(\mathrm{M}=3.73$, $\mathrm{SD}=1.00$ ) to support their work as teachers. A study found that when barriers are left unresolved and inclusive education teachers find their practices too demanding to cope with they may resort to feelings of insecurity (Florian, 2008). This can lead to those teachers questioning themselves whether they are "doing enough, doing the right thing, doing as much ... or as well as others..." (Ball, 2003, p. 220). However, it is argued that irrespective of barriers that early childhood inclusive teachers may face, if they act as inclusive leaders they may be able to transform their schools' barriers into facilitators (Sharma \& Desai, 2008). In this sense, inclusive education teachers need to recognize that leadership does not reside within one individual but is distributed across the whole school community. Ryan (2006, p. 8) argues, "concentrating leadership power in a single individual is exclusive; those who are not considered leaders are left out of leadership related activities." It is by such distributive practices that span boundaries that education barriers can be surmounted and inclusive practices enhanced (Akkerman \& Bruining, 2016).

As indicated in the research context section of this paper, Thailand enacted Education for Persons with Disabilities Act B.E. 2551 (Bualar, 2016; Vibulpatanavong, 2017) to address issues of educational equity and quality that meet the needs of all learners. The 2017 National Education Plan for education (Year 2017-2036) added to this continuous improvement in schools plan. Therefore, frist, this study makes a call for developing Thai early childhood inclusive teachers into pedagogical leaders to fulfil this mission. Teachers as leaders can contribute to cultural transformation by changing negative attitudes of their communities towards children with disabilities (Vibulpatanavong, 2017). They can do this with support from regional governments to educate parents of children with and without disabilities. Thai communities will be willing to support inclusive education if they understand it as a quality education practice that builds foundation for all Thai children to be life-long learners (Kantavong, 2018).

Second, teachers who see themselves as leaders often develop positive perspectives about inclusive education and work across various boundaries (Liasidou \& Antoniou, 2015; Ryan, 2006). On the contrary, teachers who see themselves as followers may adopt complaining attitudes about inclusive education if they felt challenged by their leaders (Carrington, Deppeler, \& Moss, 2010). In this regard, policy on teacher education and professional development must prepare teachers as pedagogical leaders enabling them to work with, rather than over, the members of their school community (Blase \& Anderson, 1995). Inclusive early childhood teachers who see themselves as leaders are democratic; they develop their inclusive dispositions grounded on leadership in activity, and not in position or role (Harris, 2005).

Finally, inclusive teachers who have strong views about collaboration are able to invite families and therapists to be part of their collective practice. Harris (2005, p. 14) posits, "leadership practice is like a group dance, where the interactions of the dancers rather than their individual actions allow us to understand what is taking place." The dance must be unity in diversity for the advancement of all children's core capability skills through educational equity. To develop a consistence practice as pedagogical leaders, less experienced teachers would need to be supported by school administrators to develop inclusive pedagogical capabilities to the level of their more experienced counterparts.

\section{Limitations of the Study}

This study has some limitations. Despite the fact that we selected a moderately large sample, size from all the six regions of Thailand, the sample was a convenient sample among the early childhood schools that described themselves as inclusive and were willing to participate in the study. Thus, the sample may not be truly representative of all the public and private inclusive kindergartens, and the results of the study cannot be generalized across the entire early childhood educational settings in Thailand. Although we collected some qualitative data in the form of interviews, we did not report this data in this paper. We also noted limitations in the analysis of our data in terms of not testing the association between qualifications and perspectives; however, this is 
not the focus of our study. The limitations of the study suggest prospects for further research. Future research can consider investigating the teachers' real time classroom practice of inclusion by using observational approach. In addition, children and families' perspectives with regard to how they are experiencing inclusive practices in the schools need to be investigated.

\section{Conclusion}

Early childhood educational settings with diverse professionals are better suited to serve diverse children in an inclusive school community. Such inclusive schools have a better understanding of the requirements of children's needs, particularly those with disabilities. They also understand that leadership is important to counter inclusive practice challenges whether, political, social, resource-related, and cultural. The results of the study provide considerable insight on the practice experiences of early childhood teachers across the six regions of Thailand. Most of the teachers are positive that they are professionally prepared to cope with teaching young children with disabilities and felt supported by families and other members of their schools' communities. We see leadership as operating at the grassroots giving these teachers a major boost to do their work, as their ratings of the questionnaire did not suggest otherwise. We recognize that almost all the participants indicated they would like to be involved in more professional training to work with children with disabilities. This is a good sign for maintaining practices according to developmental profile of children. Although some barriers have been identified such as the availability of time to plan, the supply of adequate resources and some difficulty in managing children's behaviour, we are optimistic that effective training in pedagogical leadership can assist these teachers to enhance their work with young children with disabilities in inclusive early childhood settings.

\section{Acknowledgments}

We acknowledge financial support the first author received from Mahidol University internal research funding scheme to conduct this research. Without this support, the research would have been impossible.

\section{References}

Akkerman, S. F., \& Bakker, A. (2011). Boundary crossing and boundary objects. Review of Educational Research, 81(2), 132-169. https://doi.org/10.3102/0034654311404435

Akkerman, S., \& Bruining, T. (2016). Multilevel boundary crossing in a professional development school $\begin{array}{llll}\text { partnership. Journal of the Learning } & \text { Sciences, 250-284. }\end{array}$ https://doi.org/10.1080/10508406.2016.1147448

Angelides, P. (2012). Forms of leadership that promote inclusive education in Cypriot schools. Educational Management Administration \& Leadership, 40(1), 21-36, https://doi.org/10.1177/1741143211420614

Armstrong, D. (2006). Dreaming our future: Developing democratic professional practice? Australian Educational Researcher, 33(3), 1-11. https://doi.org/10.1007/BF03216839

Ball, S. J. (2003). The teacher's soul and the terrors of performativity. Journal of Education Policy, 18(2), 215-228. https://doi.org/10.1080/0268093022000043065

Banks, J., Shevlin, M., \& McCoy, S. (2012). Disproportionality in special education: identifying children with emotional behavioural difficulties in Irish primary schools. European Journal of Special Needs Education, 27(2), 219-35. https://doi.org/10.1080/08856257.2012.669111

Blase, J., \& Anderson, G. (1995). The micropolitics of educational leadership. London: Cassell.

Bourke, R. (2017). Untangling optical illusions: The moral dilemmas and ethics in assessment practices for inclusive education. In A. Gajewski (Ed.), Ethics, equity and inclusive education (pp. 215-238). Bingley: Emerald Group Publishing. https://doi.org/10.1108/S1479-363620170000009009

Bualar, T. (2016). What has gone wrong with inclusive education in Thailand? Journal of Public Affairs, 16(2), 156-161. https://doi.org/10.1002/pa.1563

Carrington, S., Deppeler, J., \& Moss, J. (2010). Cultivating Teachers' Beliefs, Knowledge and Skills for Leading Change in Schools. Australian Journal of Teacher Education, 35(1), 1-13. https://doi.org/10.14221/ajte.2010v35n1.1

Cohen J. (1988). Statistical Power Analysis for the Behavioural Sciences. New York, NY: Routledge Academic.

Deppeler, J., Loreman, T., \& Smith, R. (2015). Teaching and learning for all. In J. Deppeler, T. Loreman, R. Smith, \& L. Florian (Eds.), International Perspectives on Inclusive Education (Vol. 7, pp. 1-10). United Kingdom: Emerald Group Publishing Limited. https://doi.org/10.1108/S1479-363620150000007010 
DiPaola, M. F., \& Walther-Thomas, C. (2003). Principals and special education: The critical role of school leaders (COPPSE Document No. IB-7). Gainesville, FL: University of Florida, Center on Personnel Studies in Special Education.

Ernst, C., \& Yip, J. (2009). Bridging boundaries: Meeting the challenge of workplace diversity. Leadership in Action, 28(1), 3-6. https://doi.org/10.1002/lia.1232

Florian, L. (2008). Special or inclusive education: Future trends. British Journal of Special Education, 35(4), 202-208. https://doi.org/10.1111/j.1467-8578.2008.00402.x

Harris, A. (2005). Crossing boundaries and breaking barriers: Distributing leadership in schools. London: iNet, Specialist Schools Trust.

Heikka, J., \& Waniganayake, M. (2011). Pedagogical leadership from a distributed perspective within the context of early childhood education. International Journal of Leadership in Education, 14, 499-512. https://doi.org/10.1080/13603124.2011.577909

Jordan, A., \& McGhie-Richmond, D. (2014). Identifying effective teaching practices in inclusive classrooms. In C. Forlin, \& T. Loreman (Eds.), Measuring inclusive education (pp. 133-162). United Kingdom: Emerald Group Publishing Limited. https://doi.org/10.1108/S1479-363620140000003023

Kantavong, P. (2018). Understanding inclusive education practices in schools under local government jurisdiction: A study of Khon Kaen Municipality in Thailand. International Journal of Inclusive Education, 22(7), 767-786. https://doi.org/10.1080/13603116.2017.1412509

Klibthong, S., \& Agbenyega, J. S. (2013). Thai Early Childhood Educators' Perspectives: Transforming Inclusive Teachers to Move Beyond Religiosity. In P. Jones (Ed.), Bringing Insider Perspectives into Inclusive Teacher learning: Potentials and Challenges for Educational Professionals (pp. 121-132). London, UK: Taylor \& Francis/Routledge.

Klibthong, S., \& Agbenyega, J. S. (2018). Exploring professional knowing, being and becoming through inclusive pedagogical approach in action (IPAA) framework. Australian Journal of Teacher Education, 43(3), 109-123. https://doi.org/10.14221/ajte.2018v43n3.7

Lalonde, M. (2013). Everything I need to know about leadership I learned as an EC educator. ChildCare Exchange, 35(2), 8-10.

Liasidou, A., \& Antoniou, A. (2015). Head teachers' leadership for social justice and inclusion. School Leadership \& Management, 35(4), 347-364. https://doi.org/10.1080/13632434.2015.1010499

Loo, J. K. Y., \& Agbenyega, J. S. (2015). A critical analysis of the Australian ECEC policy reform: An opportunity for transforming educators into pedagogical leaders? Australasian Journal of Early Childhood 40(2), 127-131. https://doi.org/10.1177/183693911504000215

Lupton, J., \& Jones, G. (2002). Practicing inclusion: A self-review framework for inclusion and special education needs: A practical guide for schools. London: East Reading of Yorkshire Council Publications.

Northouse, P. (2013). Leadership: Theory and practice (6th ed.). Thousand Oaks, CA: Sage.

Office of the Educational Council. (2016). National Education Statistics for the Year 2014-2015 (Thai language version). Retrieved from http://www.moe.go.th/moe/upload/news20/FileUpload/39719-2357.pdf

Ryan, J. (2006). Inclusive leadership and social justice for schools. Leadership and Policy in Schools, 5(1), 3-17. https://doi.org/10.1080/15700760500483995

Sharma, U., \& Desai, I. (2008). The changing roles and responsibilities of school principals relative to inclusive education. In C. Forlin, \& M. G. J. Lian (Eds.), Reform, inclusion, \& teacher education: Towards a new era of special education in the Asia-Pacific Region (pp. 153-168). UK: Routledge.

Slavin, R. E. (2017). Evidence-based reform in education. Journal of Education for Students Placed at Risk, 22(3), 178-184. https://doi.org/10.1080/10824669.2017.1334560

Thai Ministry of Education. (2017). National Education Plan (Thai language version). Advances in Social Science, Education and Humanities Research (ASSEHR) (Vol. 169). Retrieved from http://backoffice.onec.go.th/uploaded/Outstand/2017-EdPlan60-79.pdf

Timothy, S., \& Agbenyega, J. S. (2018). Inclusive school leaders' perceptions on the implementation of individual education plans. International Journal of Whole Schooling, 14(1), 1-30. https://doi.org/10.1080/13603116.2019.1642401 
Vibulpatanavong, K. (2017). Inclusive Education in Thailand. Proceedings of the International Conference of Early Childhood Education (ICECE 2017). Advances in Social Science, Education and Humanities Research (ASSEHR) (Vol. 169). https://doi.org/10.2991/icece-17.2018.16

Vorapanya, S., \& Dunlap, D. (2014). Inclusive education in Thailand: Practices and challenges. International Journal of Inclusive Education, 18(10), 1014-1028. https://doi.org/10.1080/13603116.2012.693400

Williams, J., \& Berry, A. (2016). Boundary Crossing and the Professional Learning of Teacher Educators in New International Contexts. Studying Teacher Education, 12(2), 135-151. https://doi.org/10.1080/17425964.2016.1192031

Woodrow, C., \& Busch, G. (2008). Repositioning early childhood leadership in action and activism. European Early Childhood Education Research Journal, 16(1), 83-93. https://doi.org/10.1080/13502930801897053

Yip, J., Ernst, C., \& Campbell, M. (2016). Boundary Spanning Leadership Mission Critical Perspectives from the Executive Suite: White Paper, CCL. Retrieved from https://www.ccl.org/wp-content/uploads/2015/04/BoundarySpanningLeadership.pdf

\section{Copyrights}

Copyright for this article is retained by the author(s), with first publication rights granted to the journal.

This is an open-access article distributed under the terms and conditions of the Creative Commons Attribution license (http://creativecommons.org/licenses/by/4.0/). 